Article

\title{
Effect of Roasting Temperature on Phase Transformation in Co-Reduction Roasting of Nickel Slag
}

\author{
Yunye Cao ${ }^{1,2}$, Chengyan $\mathrm{Xu}^{3}$, Yuechao Tian ${ }^{3}$ and Yanqing Hou ${ }^{2, *}$ \\ 1 School of Materials Science and Chemical Engineering, Ningbo University, Ningbo 315211, Zhejiang, China; \\ caoyunye@126.com \\ 2 State Key Laboratory of Complex Nonferrous Metal Resources Cleaning Utilization, Kunming University of \\ Science and Technology, Kunming 650093, China \\ 3 School of Civil and Resources Engineering, University of Science and Technology Beijing, Beijing 100083, \\ China; chengyan12325@163.com (C.X.); g20188093@xs.ustb.edu.cn (Y.T.) \\ * Correspondence: hhouyanqing@163.com; Tel.: +86-0871-65810517
}

Received: 10 March 2020; Accepted: 21 April 2020; Published: 24 April 2020

\begin{abstract}
Nickel slag and blast furnace dust comprise a large part of solid waste produced by the metallurgical industry. In this study, a novel method of co-reduction roasting followed by grinding/magnetic separation was proposed to collaboratively reutilize nickel slag and blast furnace dust. The nickel slag was combined with blast furnace dust to produce a Ni-Fe alloy containing $\mathrm{Cu}$ component by using the proposed method. In addition, the blast furnace dust acted not only as a reductant but also as an Fe resource. Results in this work showed that $81.62 \% \mathrm{Fe}$ and $89 \% \mathrm{Ni}$ could be recovered from nickel slag and blast furnace dust, and a Ni-Fe alloy product with $93.03 \mathrm{wt} \% \mathrm{Fe}$, $0.86 \mathrm{wt} \% \mathrm{Ni}$, and $0.49 \mathrm{wt} \% \mathrm{Cu}$ could be obtained under optimal conditions in this study. The effect of roasting temperature on phase transformation was characterized and analyzed by XRD and SEM-EDS. The results illustrated that roasting temperature was considered as the main influence to regulate the mineral phase transformation and microstructural change in roasted product. The minerals in the nickel slag finally transformed iron and augite from fayalite containing magnesium and magnetite after the disappearance/transformation of the mineral phase. The Fe-bearing minerals were first reduced in situ position of structure into metallic Fe particles and then grown into a Ni-Fe alloy with $\mathrm{Cu}$ of chain structure. The new structure, instead of the original structure, formed the homogeneous slag phase and Ni-Fe alloy with $\mathrm{Cu}$ component.
\end{abstract}

Keywords: nickel slag; roasting temperature; Ni-Fe alloy; phase transformation

\section{Introduction}

Nickel slag is the main solid waste produced during smelting in the nonferrous metallurgical industry. The production of 1 ton of nickel will lead to an average of 6-16 tons of nickel slag, with a large number of historical stockpiles in China because of the absence of an effective long-term utilization of the slag [1-3]. The nickel slag is generally composed of more than $20 \mathrm{wt} \%$ content of iron, more than $0.05 \mathrm{wt} \%$ content of $\mathrm{Ni}$, and more than $0.05 \mathrm{wt} \%$ content of $\mathrm{Cu}$ et al. This nickel slag is an unnatural ore, and the relationship between the composition and distribution of the mineral components in the nickel slag is extremely complex [4-6]. The Fe component of the nickel slag mainly exists in the fayalite phase and it's hard to separate for iron and silicon $[7,8]$, which led to the failure of conventional utilization methods, such as hydrometallurgy, and direct utilization, to realize the resource utilization of the nickel slag. Therefore, the development of new technologies for reutilizing the nickel slag is urgently needed since nickel and iron resources depends heavily on long-term imports in China. 
The blast furnace dust is a solid waste containing $C$ during the production of Fe [9]. The blast furnace dust has a lot of historical storage in China because of the absence of an effective long-term utilization. The blast furnace dust contains more than $5 \mathrm{wt} \%$ content of carbon, and more than $10 \mathrm{wt} \%$ content of iron [10-12]. Therefore, the blast furnace dust consists of valuable Fe and C. However, the efficient extraction of Fe utilization of $C$ by traditional methods [13-15] of direct utilization, physical separation, or hydrometallurgy are difficult because of their fine particle structure and complex mineralogy of blast furnace dust. This limitation has caused serious waste of valuable resources and potential risks of environmental pollution.

Studies have illustrated that nickel slag and blast furnace dust as waste solid should be disposed of and reutilized urgently. At present, the technology of coal-based direct reduction roasting following magnetic separation has been demonstrated as an effective technology to process refractory iron ore [16-20]. In this study, a novel method called co-reduction roasting was proposed for the comprehensive utilization of nickel slag and blast furnace dust, considering that the nickel slag containing Fe and blast furnace dust containing Fe and $C$ have complementary mineral and chemical components. The effect of co-reduction roasting temperature as a main regulation influence condition for the disappearance/transformation of mineral phase and microstructural change was explored in this study.

\section{Materials}

Nickel slag and blast furnace dust came from an environmental-protection company in Beijing. X-Ray Diffraction (XRD) was employed to analyze the mineral composition of the nickel slag. The results showed that the slag mainly contained Fe-bearing mineral in fayalite containing magnesium $\left((\mathrm{Fe}, \mathrm{Mg})_{2} \mathrm{SiO}_{4}\right)$, and a small proportion in the magnetite $\left(\mathrm{Fe}_{3} \mathrm{O}_{4}\right)$ in Figure 1.

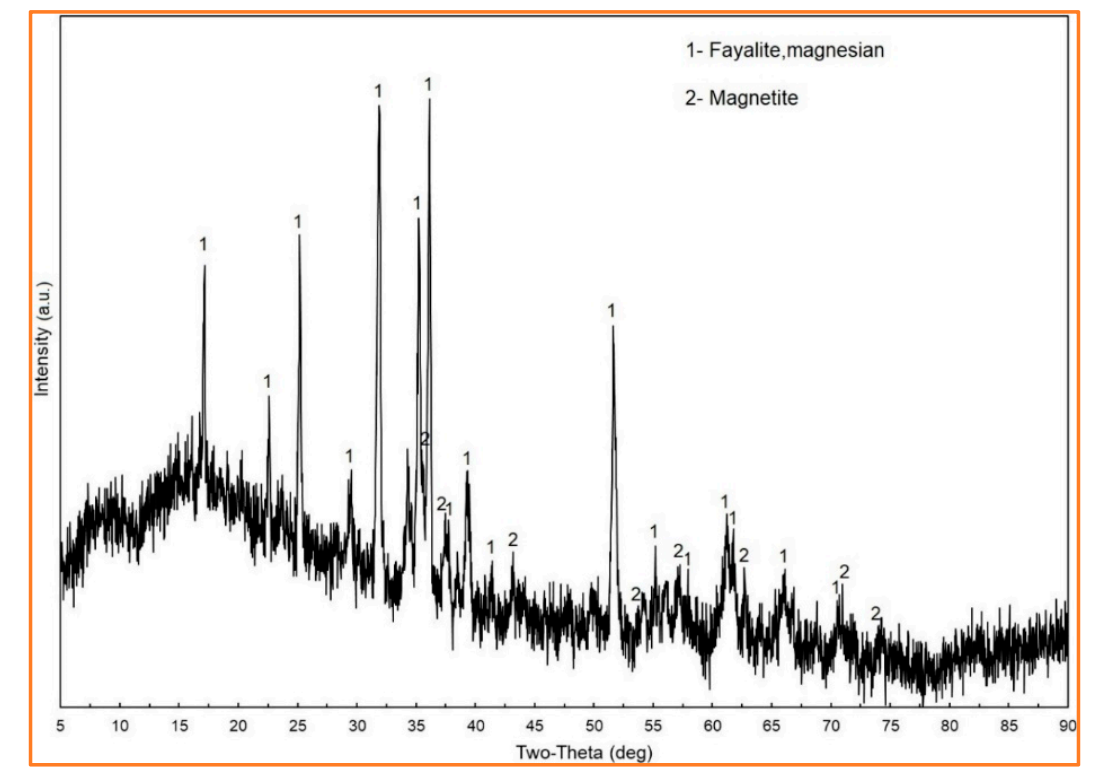

Figure 1. X-Ray Diffraction (XRD) analysis result of nickel slag.

SEM-EDS (scanning electron microscope with energy dispersive $X$-ray spectrometer) was also performed to further identify the mineral distribution and original structure of nickel slag. The analysis results are shown in Figure 2.

The SEM-EDS analysis results of Figure 2 illustrated that the Fe-bearing mineral appeared at point 1 and point 2, which represented fayalite containing magnesium, and a part of the fayalite contained aluminum and calcium (point 1). Figure 2 didn't show the magnetite phase particles because the low magnetite content may have consisted of very fine grans. Figure 2 also showed that Ni existed 
in fayalite with magnesium and Fe-S-Cu-Ni alloy particles. Chemical analysis showed that the nickel slag contained following elements: Fe, $39.46 \mathrm{wt} \%$; Ni, $0.43 \mathrm{wt} \%$; P, $0.02 \mathrm{wt} \%$; S, $0.69 \mathrm{wt} \%$.

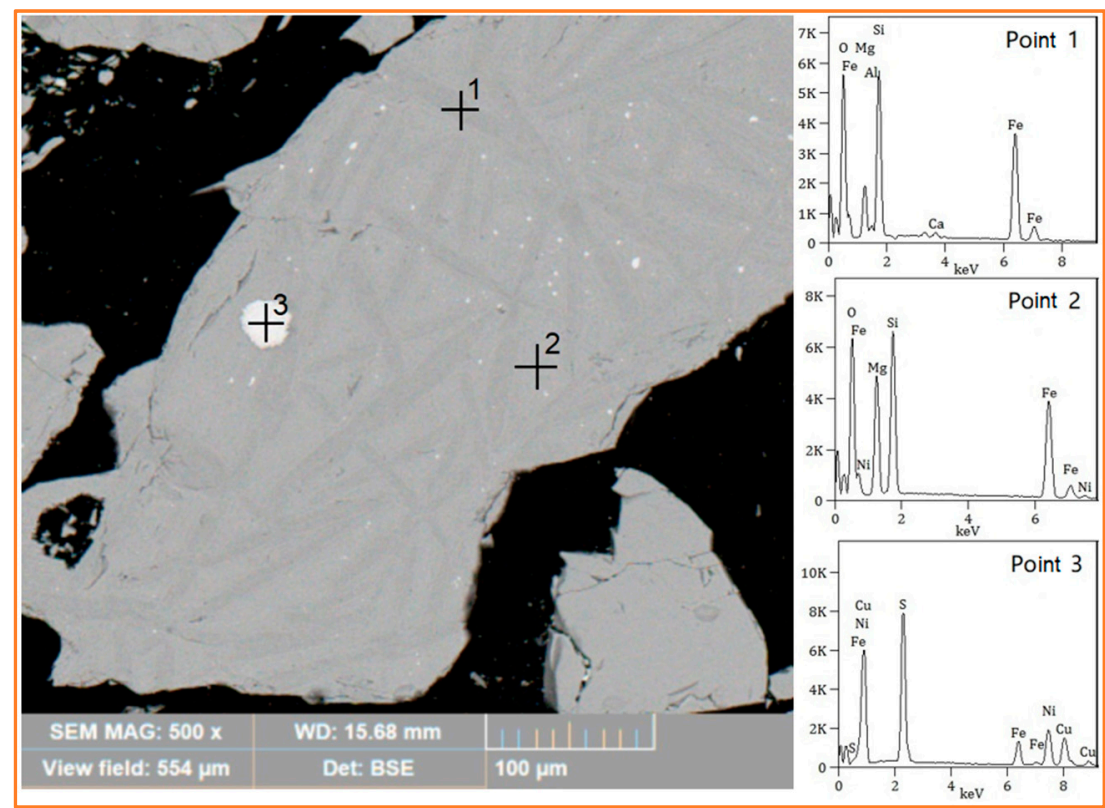

Figure 2. SEM-EDS (scanning electron microscope with energy dispersive X-ray spectrometer) analysis results of nickel slag.

As solid waste, blast furnace dust was used as a reductant in this work, and the result from its proximate analysis is shown in Table 1 . Chemical analysis showed that the blast furnace dust (bfd) contained the following elements: Fe, $35.54 w \mathrm{t} \% ; \mathrm{P}, 0.17 \mathrm{wt} \%$;, $0.43 \mathrm{wt} \%$.

Table 1. The proximate analysis result of reductant.

\begin{tabular}{cccccc}
\hline Reductant & Code & $\mathbf{M}_{\text {ad }}(\mathbf{w t} \%)$ & $\mathbf{A}_{\text {ad }}(\mathbf{w t} \%)$ & $\mathbf{V}_{\text {ad }}(\mathbf{w t} \%)$ & FC $_{\text {ad }}(\mathbf{w t} \%)$ \\
\hline blast furnace dust & bfd & 2.62 & 68.04 & 8.79 & 20.55 \\
\hline
\end{tabular}

Note: M: moisture, A: ash; V: volatiles, FC: fixed carbon; ad: air dried basis.

\section{Experimental Details}

\subsection{Experimental Procedure}

The nickel slag, reductant, and additive with different mass ratios were mixed. The mass of $\mathrm{Ni}$ slag was $20 \mathrm{~g}$ for every experiment. The method of mixture was roll shifting method, i.e., we placed the sample in the center of the plastic cloth, and then lifted one corner of the cloth to make the sample roll on the cloth. When the sample rolled over the diagonal of the cloth for a certain distance, we would lift the corresponding other corner to make the sample roll in the same way. This action was repeated several times. The mixture was placed in graphite crucible, which was then transferred into a muffle furnace with a temperature programmer for co-reduction roasting at different temperatures and times. The muffle furnace was manufactured by Beijing Flame Experimental equipment Co. Ltd. in China, and model BFX-16B. The air-cooled roasted product underwent a two-stage grinding-magnetic separation process with a magnetic field strength of $140 \mathrm{mT}$ to obtain the magnetic product called Ni-Fe alloy product. The magnetic separator was manufactured by No. 102 plant of Sichuan geological bureau in China, and model XCGS- $\Phi 50$. The dosages of bfd and additive, respectively, were expressed in percentages as ratios of masses relative to the nickel slag. $\mathrm{CaCO}_{3}$ was selected as an additive because the calcium component can be used to adjust the microstructure of the roasted products [21-23]. 


\subsection{Analysis and Characterization}

The main evaluation indices of the Ni-Fe alloy product were Fe content, Fe recovery rate, Ni content, and Ni recovery rate. The Fe recovery rate referred to the Ni-Fe alloy product from the total Fe contained in the nickel slag and blast furnace dust.

$$
\begin{aligned}
& \text { Fe recovery rate }=\left(\mathrm{W}_{1} \times \beta_{1}\right) /\left(\mathrm{W}_{0} \times \beta_{0}+\mathrm{W}_{2} \times \beta_{2}\right) \times 100 \mathrm{wt} \% \\
& \text { Ni recovery rate }=\left(\mathrm{W}_{1} \times \beta_{3}\right) /\left(\mathrm{W}_{0} \times \beta_{4}+\mathrm{W}_{2} \times \beta_{5}\right) \times 100 \mathrm{wt} \%
\end{aligned}
$$

where $\mathrm{W}_{0}$ was the weight of nickel slag, $\mathrm{W}_{1}$ was the weight of Ni-Fe alloy, and $\mathrm{W}_{2}$ was the weight of bfd. $\beta_{0}$ was the Fe content of nickel slag, $\beta_{1}$ was the Fe content of Ni-Fe alloy, $\beta_{2}$ was the Fe content of bfd, $\beta_{3}$ was the Ni content of Ni-Fe alloy, $\beta_{4}$ was the Ni content of nickel slag, and $\beta_{5}$ was the Ni content of bfd, respectively.

The effect of roasting temperature on phase transformation in the co-reduction in nickel slag and bfd was investigated by XRD and SEM-EDS. XRD was used to study the disappearance/transformation of the mineral phase in the roasted products obtained under different roasting temperatures. SEM-EDS provided direct visual evidence of the effects of roasting temperature effects on the inter-microstructure evolution and mineral phase transformation of different roasted products. The XRD equipment was manufactured by PANalytical B.V. in the Netherlands with model Empyrean. The XRD patterns were recorded using an $\mathrm{X}$-ray diffractometer $\left(\mathrm{Cu}\right.$ target) at $5^{\circ}-90^{\circ}$ scanning range. The SEM equipment was manufactured in Czech with model Tescan VGA3, and the EDS equipment with model NORAN System 7 (Thermo Fisher Scientific, Inc, Waltham, MA, USA).

\section{Results and Discussion}

\subsection{Effect of Roasting Temperature on the Co-Reduction Process}

The effect of roasting temperature on the co-reduction roasting of nickel slag and bfd was investigated. The influence on the Ni-Fe alloy indices were examined in the following conditions: co-reduction time, $110 \mathrm{~min} ; \mathrm{CaCO}_{3}$ dosage, $30 \mathrm{wt} \%$; bfd dosage, $32 \mathrm{wt} \%$. The experimental results were shown in Figure 3.

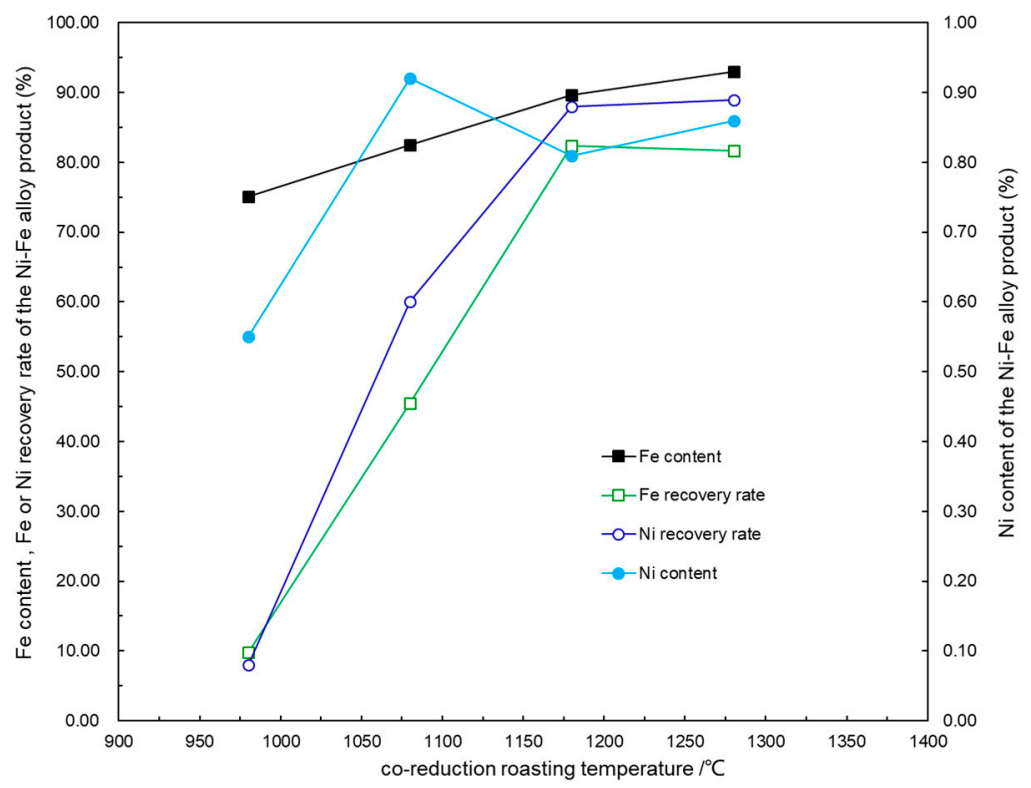

Figure 3. Effect of roasting temperature on the Ni-Fe alloy indices. 
With the increase in roasting temperature, the Fe and Ni content, Fe recovery rate, and Ni recovery rate rapidly and then gently increased. A Ni-Fe alloy with the following characteristics were obtained at roasting temperature $980{ }^{\circ} \mathrm{C}$ : Fe content, $75.09 \mathrm{wt} \%$; Fe recovery rate, $9.75 \%$; Ni content, $0.55 \mathrm{wt} \%$; and $\mathrm{Ni}$ recovery rate, $8 \%$. When the co-reduction temperature was increased to $1180{ }^{\circ} \mathrm{C}$, the Fe content increased to $89.68 \mathrm{wt} \%$, the Fe recovery rate increased to $82.39 \%$, the Ni content increased to $0.81 \mathrm{wt} \%$, and the Ni recovery rate increased to $88 \%$. When the co-reduction temperature further increased to $1280{ }^{\circ} \mathrm{C}$, the Fe content increased to $93.03 \mathrm{wt} \%$ and the Ni recovery rate increased to $89 \%$ in the $\mathrm{Ni}-\mathrm{Fe}$ alloy. Therefore, the optimum roasting temperature for this co-reduction roasting was set at $1280^{\circ} \mathrm{C}$. The results illustrated that increasing the roasting temperature was successful at reducing the $\mathrm{Mg}$-bearing fayalite into metallic iron and the formation of Ni-Fe alloy particles.

\subsection{Effect of bfd Dosage on the Co-Reduction Process}

The effect of bfd dosage on the co-reduction roasting of nickel slag and bfd was also examined. The experimental conditions were as follows: roasting temperature, $1280{ }^{\circ} \mathrm{C}$; co-reduction time, $110 \mathrm{~min}$; $\mathrm{CaCO}_{3}$ dosage, $30 \mathrm{wt} \%$, and various bfd dosages. The results were shown in Figure 4.

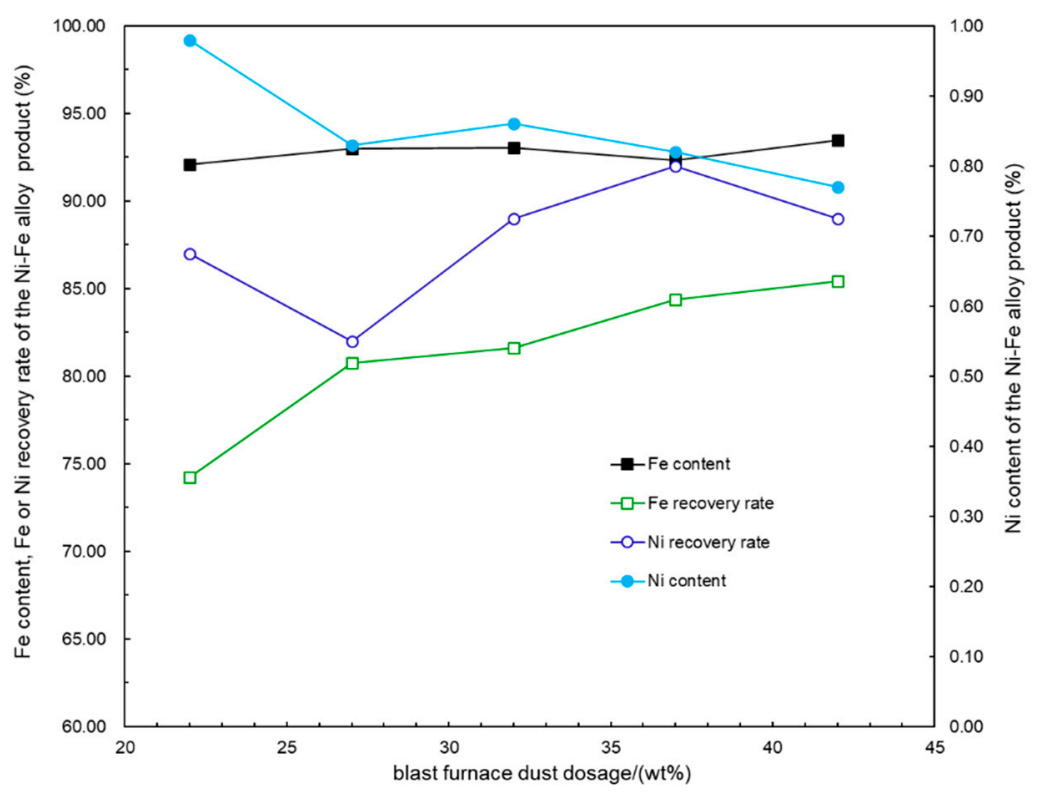

Figure 4. Effect of bfd dosage on the Ni-Fe alloy indices.

As the bfd dosage increased, the Fe recovery rate tended to rise, the Fe content generally remained unchanged at $90 \mathrm{wt} \%$, and the $\mathrm{Ni}$ content and recovery rate showed no regular trend. When the bdf dosage was increased from $22 \mathrm{w} t \%$ to $37 \mathrm{wt} \%$, the Fe content increased from $92.10 \mathrm{wt} \%$ to $92.30 \mathrm{wt} \%$, the Fe recovery rate increased from $74.22 \%$ to $84.39 \%$, the Ni content changed from $0.98 \mathrm{wt} \%$ to $0.82 \mathrm{wt} \%$, and the Ni recovery rate increased from $87 \%$ to $92 \%$ in the Ni-Fe alloy. However, increasing the bfd dosage from $37 \mathrm{wt} \%$ to $42 \mathrm{wt} \%$ did not remarkably increase the Fe recovery rate, and the Ni recovery rate decreased. Thus, Fe and Ni resources were wasted. Therefore, the optimal bfd dosage in this work was set to $32 \mathrm{wt} \%$.

\subsection{Effect of Roasting Time on the Co-Reduction Process}

The effect of roasting time on the co-reduction roasting of nickel slag and bfd was assessed. The experimental conditions were as follows: co-reduction roasting temperature, $1280{ }^{\circ} \mathrm{C}$; bfd dosage, $32 \mathrm{wt} \%$; $\mathrm{CaCO}_{3}$ dosage, $30 \mathrm{wt} \%$; and varied co-reduction roasting times. The results are shown in Figure 5. 


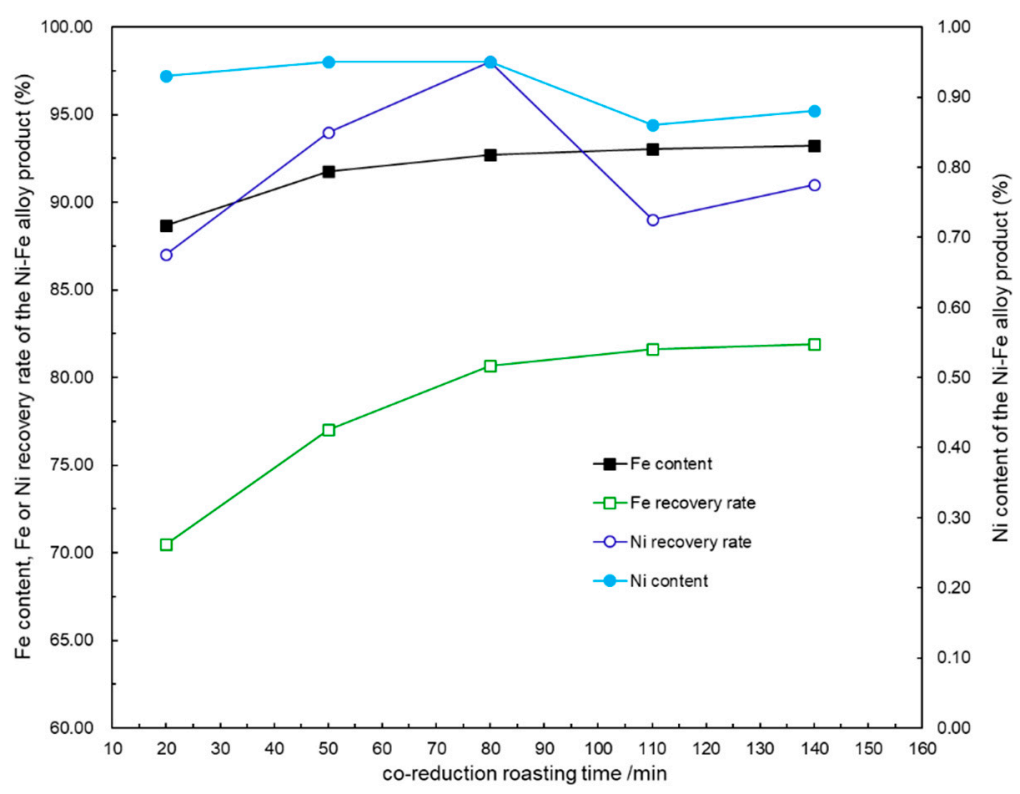

Figure 5. Effect of roasting time on the Ni-Fe alloy indices.

The results in Figure 5 illustrate that increasing the roasting time from 20 to $140 \mathrm{~min}$ resulted in an increase in Fe content from 88.68 to $93.22 \mathrm{wt} \%$, an increase in Fe recovery rate from $70.48 \%$ to $81.88 \%$, and an increase in Ni recovery rate from $87 \%$ to $91 \%$. However, the Ni content decreased from $0.93 \mathrm{wt} \%$ to $0.88 \mathrm{wt} \%$. Hence, increasing the roasting time was beneficial to the reduction in the fayalite containing magnesium to metallic iron, but too long a roasting time would lead to a waste of energy. Therefore, the optimal roasting time was set to $110 \mathrm{~min}$ in this work. An Ni-Fe alloy with $93.03 \mathrm{wt} \% \mathrm{Fe}, 81.62 \% \mathrm{Fe}$ recovery rate, $0.86 \mathrm{wt} \% \mathrm{Ni}$ content, and $89 \% \mathrm{Ni}$ recovery rate can be obtained at the following co-reduction roasting-grinding/magnetic separation conditions: roasting temperature, $1280{ }^{\circ} \mathrm{C} ; \mathrm{bfd}$ dosage, $32 \mathrm{wt} \% ; \mathrm{CaCO}_{3}$ dosage, $30 \mathrm{wt} \%$; and two-stage grinding/magnetic separation.

\section{Effect of Roasting Temperature on the Phase Transformation}

\subsection{XRD Analysis}

To study the effect of roasting temperature on the disappearance/transformation of the minerals phase during the co-reduction roasting process, different kinds of roasted products were analyzed via XRD. The analysis results were shown in Figure 6.

The XRD results in Figure 6 showed that roasting temperature influenced the disappearance/ transformation of the mineral phase in the co-reduction roasting of nickel slag and bfd. A proportion of the fayalite (Figure 1) from nickel slag was converted to the mineral phase of forsterite ferroan $\left(\mathrm{Mg}_{1.38} \mathrm{Fe}_{0.61} \mathrm{Ca}_{0.01} \mathrm{SiO}_{4}\right)$ and augite $\left(\left(\mathrm{CaMg}_{0.74} \mathrm{Fe}_{0.25}\right) \mathrm{Si}_{2} \mathrm{O}_{6}\right)$ when the roasting temperature was $880^{\circ} \mathrm{C}$. Increasing the roasting temperature to $980^{\circ} \mathrm{C}$ resulted in the disappearance of the magnetite phase, and a large proportion of the fayalite phase was transformed to forsterite ferroan phase. When the co-reduction temperature was further increased to $1180^{\circ} \mathrm{C}$, the fayalite and forsterite ferroan phases were generally transformed to the akermanite, augite and metallic iron phases in the roasted product. Akermanite composition was $\mathrm{Ca}_{2} \mathrm{Mg}\left(\mathrm{Si}_{2} \mathrm{O}_{7}\right)$ but substitution between $\mathrm{Ca}$ and $\mathrm{Na}$, between $\mathrm{Mg}$ and Al-Fe as well could occur in the co-reduction process to become $\left(\mathrm{Ca}_{1.53} \mathrm{Na}_{0.51}\right)\left(\mathrm{Mg}_{0.39} \mathrm{Al}_{0.41} \mathrm{Fe}_{0.16}\right)$ $\mathrm{Si}_{2.0} \mathrm{O}_{7}$. The raw mineral phase of the mixture basically transformed to the mineral phase of iron and augite, which were the main components of the roasted products as the roasting temperature was increased to $1280^{\circ} \mathrm{C}$. The $\mathrm{XRD}$ results showed the roasting temperature could effectively regulate the disappearance/transformation of the mineral phase during the co-reduction roasting of nickel slag and bfd. 


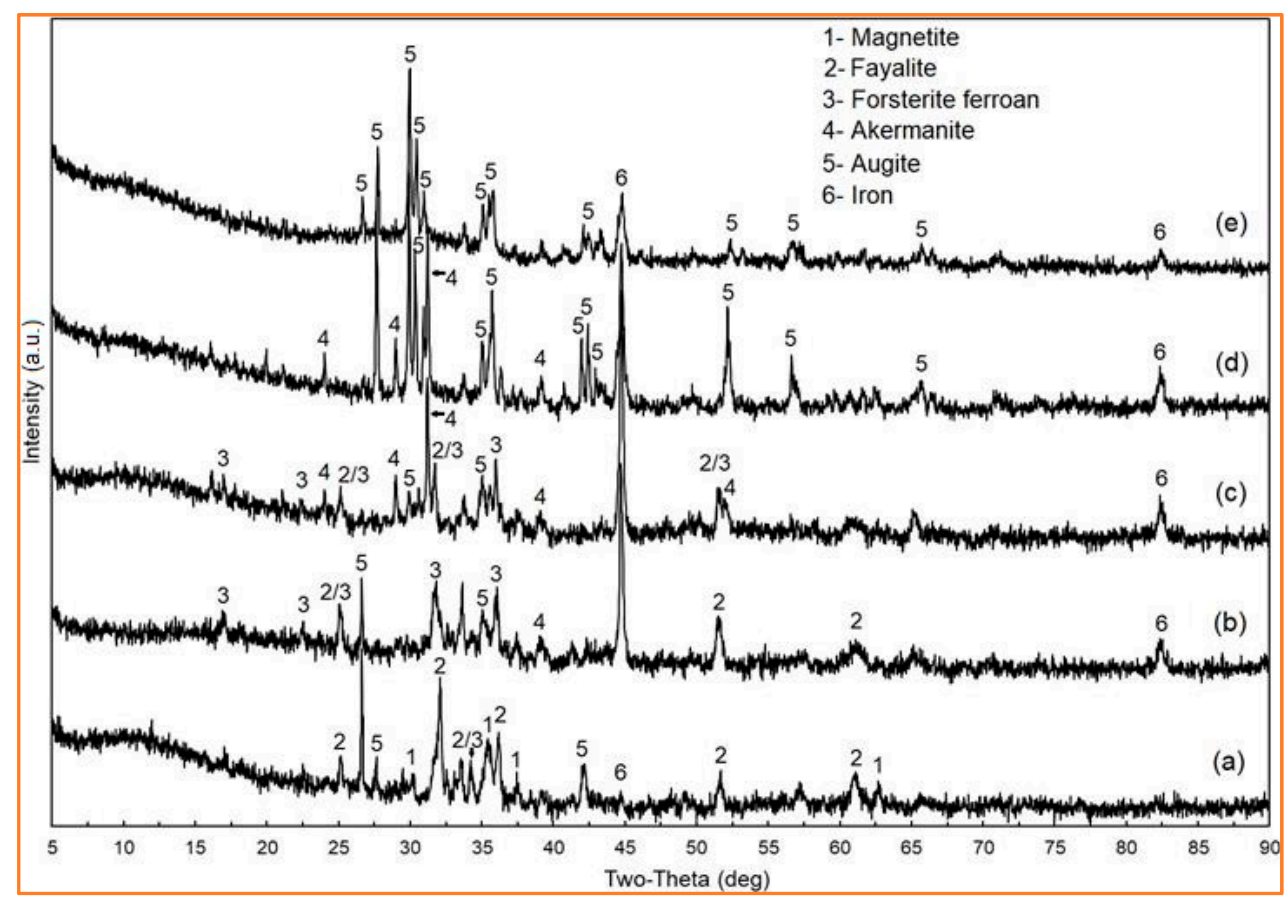

Figure 6. The disappearance/transformation of minerals phase of the different roasted products: (a) $880^{\circ} \mathrm{C},\left(\right.$ b) $980{ }^{\circ} \mathrm{C}$, (c) $1080{ }^{\circ} \mathrm{C},\left(\right.$ d) $1180{ }^{\circ} \mathrm{C}$, (e) $1280{ }^{\circ} \mathrm{C}$.

\subsection{Analysis of the Microstructural Variation in the Roasted Products}

The microstructural variation in the roasted products at different roasting temperatures were investigated by SEM-EDS, and the results were shown in Figure 7.

As shown in the Figure 7, the roasting temperature could effectively regulate the microstructural change of the roasted products and promote the separation of substances. The anaysis result of point 1 showed that the mineral component of fayalite changed, but the structure of nickel slag superficially remained unchanged as the roasting temperture was increased to $880^{\circ} \mathrm{C}$. Meanwhile, at point 2, the metallic iron particles consisted of $\mathrm{Ni}-\mathrm{Fe}-\mathrm{Cu}$. When the co-reduction temperature was increased to $1080{ }^{\circ} \mathrm{C}$, the original structure of nickel slag was destroyed, and two new structures (point 5 and point 6) were formed. The SEM-EDS result in Figure 7c also illustrated that minerals bearing iron (XRD-2,3) grew into tiny Ni-Fe alloy particles after the structure was destroyed in situ. The SEM result in Figure $7 \mathrm{~d}$ showed that the original strucutre of the mixture was largely transformend into a new one when the co-reduction roasting temperature was further increased to $1180^{\circ} \mathrm{C}$. The composition of point 7 represented a new strucutre component, i.e., the augite (XRD-5) phase with aluminum. The metallic iron particles grew into Ni-Fe alloy particles after migration-aggregation. When the roasting temperature was increased to $1280^{\circ} \mathrm{C}$, the component of the grey area was homogeneous in Figure 7e, i.e., augite with aluminum, according to point 9 and XRD- 5, and the Ni-Fe alloy particles has grown into Ni-Fe chain structure. The SEM-EDS results showed that as the roasting temperature was increased, the original structure of mixture was destroyed at first and then recombined into a new structure with the homogeneous slag phase and Ni-Fe chain. The structure of the minerals with Fe was first reduced in situ into metallic iron, grew by the aggregation of the Ni-Fe alloy particles, and then restructured into a chain of Ni-Fe alloy. 

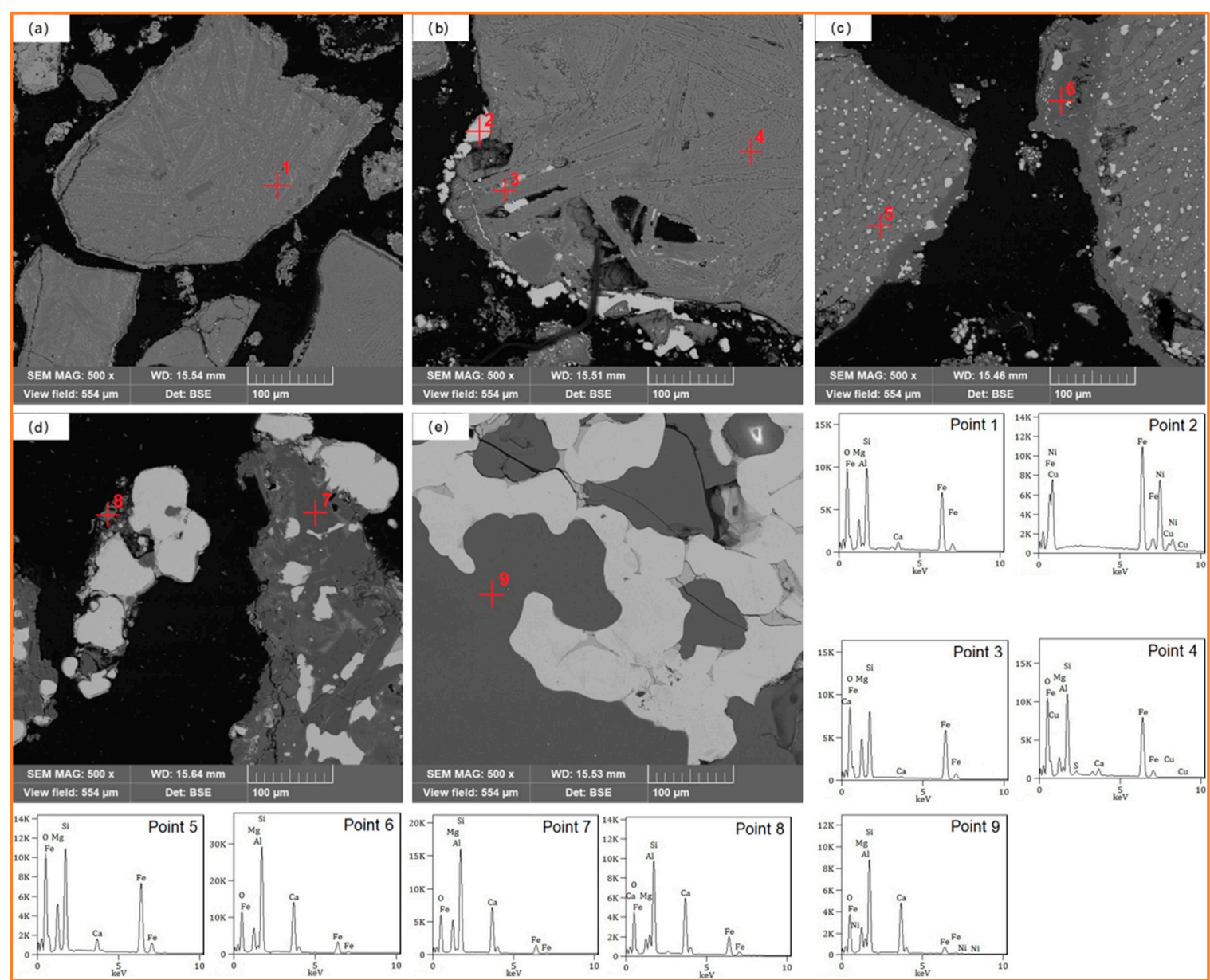

Figure 7. The microstructural change in different roasted products: (a) $880^{\circ} \mathrm{C},(\mathbf{b}) 980{ }^{\circ} \mathrm{C},(\mathbf{c}) 1080{ }^{\circ} \mathrm{C}$, (d) $1180{ }^{\circ} \mathrm{C}$, (e) $1280{ }^{\circ} \mathrm{C}$.

\subsection{Analysis of the Ni-Fe Alloy Product}

The XRD analysis results and Ni-Fe-Cu distribution in the SEM image of the Ni-Fe alloy product with $93.03 \mathrm{wt} \% \mathrm{Fe}, 81.62 \% \mathrm{Fe}$ recovery rate, $0.86 \mathrm{wt} \% \mathrm{Ni}$, and $89 \% \mathrm{Ni}$ recovery rate obtained from the previous co-reduction roasting-grinding/magnetic separation condition are shown in Figure 8.

The results in Figure 8 illustrated that Fe in the Ni-Fe alloy product exhibited a high diffraction peak with an almost pure iron phase. The distribution of $\mathrm{Fe}, \mathrm{Ni}$ and $\mathrm{Cu}$ in the SEM image shows that the majority of $\mathrm{Fe}$ overlapped with $\mathrm{Ni}$ and $\mathrm{Cu}$ in the observed area. Thus, the magnetic product from the co-redution roasting-grinding/magnetic separation was an Ni-Fe alloy product with $\mathrm{Cu}$ component. The chemical analysis of the Ni-Fe alloy product showed that the $\mathrm{Cu}$ content was $0.49 \mathrm{wt} \%$. 

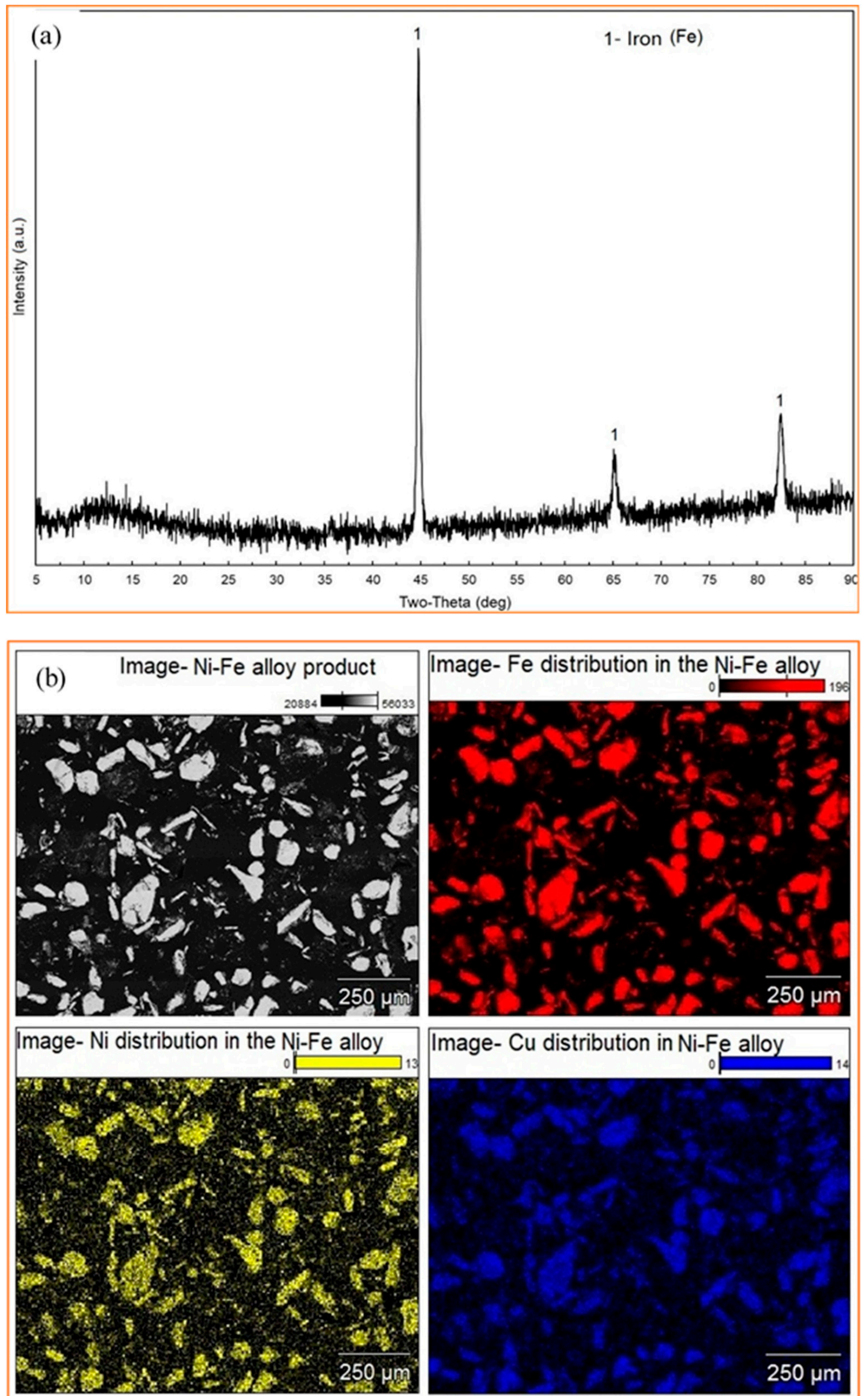

Figure 8. Analysis results of alloy product: (a) XRD patterns; (b) Fe, Ni and Cu distribution. 


\section{Conclusions}

A novel co-reduction roasting was proposed to realize a collaborative reutilization of nickel slag and blast furnace dust as solid wastes produced in metallurgical industry. An Ni-Fe alloy product as a raw material for producing weatherproof structural steel with $93.03 \mathrm{wt} \% \mathrm{Fe}, 81.62 \%$ Fe recovery rate, $0.86 \mathrm{wt} \% \mathrm{Ni}, 89 \% \mathrm{Ni}$ recovery rate, $0.49 \mathrm{wt} \% \mathrm{Cu}$ content can be obtained under the following conditions in this work: roasting temperature, $1280{ }^{\circ} \mathrm{C}$; blast furnace dust dosage, $32 \mathrm{wt} \%$; $\mathrm{CaCO}_{3}$ dosage, $30 \mathrm{wt} \%$; co-reduction roasting time, $110 \mathrm{~min}$; and two-stage process of grinding/magnetic separation. In addition, it is believed that the tailings magnetic separation could be used as construction materials.

XRD and SEM-EDS results showed that the roasting temperature could effectively regulate the mineral phase transformation and inter-microstructure change in the roasted product during the co-reduction roasting process. Increasing roasting temperature gradually transformed the mineral phase of Mg-bearing fayalite and magnetite to iron phase and augite phase. The original structure was destroyed in situ, and then a new structure containing homogeneous slag phase and Ni-Fe alloy phases was formed through the co-reduction roasting process. The Fe-bearing minerals were reduced in situ position into metallic iron particles. Finally, the metallic iron particles underwent migration and aggregation to grow into an $\mathrm{Ni}-\mathrm{Fe}$ alloy product containing a $\mathrm{Cu}$ component chain structure.

Author Contributions: Y.C. provided fundings support, designed the experiment, wrote the manuscript, and analyzed mechanism. C.X. provided test results and interpretation of data. Y.T. contributed to the operation of the experiment and data analysis. Y.H. contributed to the guidance of the experiment and the writing of the manuscript. All authors have read and agreed to the final version of the manuscript.

Funding: This research was funded by the Open Foundation of State Key Laboratory of Complex Nonferrous Metal Resources Clean Utilization, Kunming University of Science and Technology (Grant No. CNMRCUKF2006) and the Fundamental Research Funds for the Provincial Universities of Zhejiang (Grant No. 019-422001832).

Acknowledgments: The authors would like to thank the Open Foundation of State Key Laboratory of Complex Nonferrous Metal Resources Clean Utilization, Kunming University of Science and Technology (Grant No. CNMRCUKF2006) and the Fundamental Research Funds for the Provincial Universities of Zhejiang (Grant No. 019-422001832) for financial support.

Conflicts of Interest: The authors declare no conflict of interest.

\section{References}

1. China Nonferrous Metals Industry Association. The Yearbook of Nonferrous Metals Industry of China 2018; China Nonferrous Metals Industry Association: Beijing, China, 2019.

2. Zhang, Q.L.; Ji, T.; Yang, Z.X.; Wang, C.Q.; Wu, H.C. Influence of different activators on microstructure and strength of alkali-activated nickel slag cementitious materials. Constr. Build. Mater. 2020, 235, 117449. [CrossRef]

3. Singh, J.; Singh, S.P. Geopolymerization of solid waste of non-ferrous metallurgy —A review. J. Environ. Manag. 2019, 251, 109571. [CrossRef] [PubMed]

4. Wang, Q.; Yu, C.J.; Yang, J.M.; Chong, L.L.; Xu, X.C.; Xu, X.C.; Wu, Q.S. Influence of nickel slag powders on properties of magnesium potassium phosphate cement paste. Constr. Build. Mater. 2019, 205, 668-678. [CrossRef]

5. Liu, X.M.; Gao, S.L.; Li, J.; Kou, J.; Sun, C.B. Process mineralogy of Jinchuan nickel slag in a settlement furnace. Chin. J. Eng. 2017, 39, 349-353.

6. Huang, F.R.; Liao, Y.L.; Zhou, J.; Wang, Y.Y.; Li, H. Selective recovery of valuable metals from nickel converter slag at elevated temperature with sulfuric acid solution. Sep. Purif. Technol. 2015, 156, 572-581. [CrossRef]

7. Wu, Q.S.; Wu, Y.; Tong, W.H.; Ma, H.G. Utilization of nickel slag as raw material in the production of Portland cement for road construction. Constr. Build. Mater. 2018, 193, 426-434. [CrossRef]

8. Li, Y.J.; Papangelakis, V.G.; Perederiy, I. High pressure oxidative acid leaching of nickel smelter slag: Characterization of feed and residue. Hydrometallurgy 2009, 97, 185-193. [CrossRef]

9. $\mathrm{Xu}$, J.; Wang, N.; Zhou, Z.Y.; Chen, M.; Wang, P.F. Experimental and numerical studies of the gas-molten reduction behavior of blast furnace dust particles during in-flight process. Powder Technol. 2020, 361, 226-237. [CrossRef] 
10. Hu, W.T.; Xia, H.W.; Pan, D.L.; Wei, X.L.; Li, J.; Dai, X.J.; Yang, F.H.; Lu, X.; Wang, H.J. Difference of zinc volatility in diverse carrier minerals: The critical limit of blast furnace dust recycle. Miner. Eng. 2018, 116, 24-31. [CrossRef]

11. Xu, J.; Wang, N.; Chen, M.; Zhou, Z.Y.; Wang, P.F. Evaluation of reduction behavior of blast furnace dust particles during in-flight process with experiment aided mathematical modeling. Appl. Math. Model. 2019, 75, 535-552. [CrossRef]

12. Wu, Z.J.; Wang, L.C.; Gao, Z.F.; Liu, W.M.; Wu, X.R. Recycling blast furnace dust into metals (Al, Zn and Ti)-doped hematite with enhanced photocatalytic activity. J. Environ. Chem. Eng. 2016, 4, 341-345. [CrossRef]

13. Zeng, G.W. Review on utilization technologies of blast-furnace gas sludge. Environ. Prot. Chem. Ind. 2015, 35, 279-283.

14. Makkonen, H.T.; Heino, J.; Laitila, L.; Hiltunen, A.; Pöyliö, E.; Härkki, J. Optimisation of steel plant recycling in Finland: Dusts, scales and sludge. Resour. Conserv. Recy. 2002, 35, 77-84. [CrossRef]

15. Hu, T.Y.; Sun, T.C.; Kou, J.; Geng, C.; Wang, X.P.; Chen, C. Recovering titanium and iron by co-reduction roasting of seaside titanomagnetite and blast furnace dust. Int. J. Miner. Process. 2017, 165, 28-33. [CrossRef]

16. Sun, Y.S.; Zhou, W.T.; Han, Y.X.; Li, Y.J. Effect of different additives on reaction characteristics of fluorapatite during coal-based reduction of iron ore. Metals 2019, 9, 923. [CrossRef]

17. Gao, P.; Li, G.F.; Han, Y.X.; Sun, Y.S. Reaction behavior of phosphorus in coal-based reduction of an oolitic hematite ore and pre-dephosphorization of reduced iron. Metals 2016, 6, 82. [CrossRef]

18. Li, Y.L.; Sun, T.C.; Kou, J.; Guo, Q.; Xu, C.Y. Study on phosphorus removal of high-phosphorus oolitic hematite by coal-based direct reduction and magnetic separation. Miner. Process. Extr. Metall. Rev. 2014, 35, 66-73. [CrossRef]

19. Wang, X.P.; Sun, T.C.; Chen, C.; Kou, J. Effects of $\mathrm{Na}_{2} \mathrm{SO}_{4}$ on iron and nickel reduction in a high-iron and low-nickel laterite ore. Int. J. Min. Met. Mater. 2018, 25, 383-390. [CrossRef]

20. Geng, C.; Sun, T.C.; Ma, Y.W.; Xu, C.Y.; Yang, H.F. Effects of embedding direct reduction followed by magnetic separation on recovering titanium and iron of beach titanomagnetite concentrate. J. Iron Steel Res. Int. 2017, 24, 156-164. [CrossRef]

21. Sun, Y.S.; Han, Y.X.; Li, Y.F.; Li, Y.J. Formation and characterization of metallic iron grains in coal-based reduction of oolitic iron ore. Int. J. Miner. Metall. Mater. 2017, 24, 123-129. [CrossRef]

22. Li, X.M.; Wen, Z.Y.; Li, Y.; Yang, H.B.; Xing, X.D. Improvement of carbothermic reduction of nickel slag by addition of $\mathrm{CaCO}_{3}$. Trans. Nonferr. Met. Soc. China 2019, 29, 2658-2666. [CrossRef]

23. Cao, Z.C.; Sun, T.C.; Xue, X.; Liu, Z.H. Iron recovery from discarded copper slag in a RHF direct reduction and subsequent grinding/magnetic separation process. Minerals 2016, 6, 119. [CrossRef] 